\title{
Advanced satellite technique for volcanic activity monitoring and early warning
}

\author{
Nicola Pergola $\left({ }^{1}\right)\left({ }^{2}\right)$, Francesco Marchese $\left({ }^{1}\right)$, Valerio Tramutoli $\left({ }^{2}\right)\left({ }^{1}\right)$, \\ Carolina Filizzola $\left({ }^{1}\right)$ and Maurizio Ciampa $\left({ }^{2}\right)$ \\ $\left.{ }^{1}{ }^{(}\right)$Istituto di Metodologie per l'Analisi Ambientale (IMAA, CNR), Tito Scalo (PZ), Italy \\ $\left(^{2}\right)$ Dipartimento di Ingegneria e Fisica dell'Ambiente, Università degli Studi della Basilicata, Potenza, Italy
}

\begin{abstract}
Nowadays, satellite remote sensing is an important tool for volcanic activity monitoring, thanks to several operational satellite platforms providing data everywhere with high observational frequencies and generally at low cost. Among different techniques available, an advanced satellite method, named RST (Robust Satellite Technique), based on the multitemporal analysis of satellite data, has shown a high capability in volcanic activity monitoring. This approach has proved capable of identifying and tracking volcanic ash cloud and of correctly detecting and monitoring volcanic thermal anomalies. This paper analyzes some recent results, obtained applying this approach to the last eruptive events of Mt. Etna using both polar and geostationary satellites. In particular, for the first time, this approach is implemented on the present geostationary platform MSG-SEVIRI, with 15 min of temporal resolution. Preliminary results, together with a future potential of this implementation, are shown and discussed. Moreover, a differential RST index in time domain is also proposed for near real-time application, as a possible contribution to the development of an efficient early warning satellite system for volcanic hazard mitigation.
\end{abstract}

Key words Etna-AVHRR - SEVIRI - ash cloud detection - volcanic thermal anomalies - Robust Satellite Techniques - early warning

\section{Introduction}

Many volcanoes in the world are located in inaccessible areas, where traditional monitoring devices are generally difficult to use. Since volcanic ash, even at great distances from the eruption sites, may determine serious damage to aircraft engines, volcanoes pose a serious threat for both crew and passengers, increasing costs for companies in the aviation industry (Casadevall, 1994).

Mailing address: Dr. Nicola Pergola, Istituto di Metodologie per l'Analisi Ambientale, CNR, 85050 Tito Scalo (PZ), Italy; e-mail: pergola@imaa.cnr.it
For volcanoes located in very densely populated regions, problems may also arise because of lava flow, pyroclastic emissions, etc., which are potentially dangerous both for local residents and infrastructures.

Therefore, to mitigate volcanic risk, reliable monitoring systems are required, which should be capable of promptly identifying volcanic ash plumes, discriminating them from meteorological clouds in whatever observational condition (i.e. in daytime/night-time, different seasonal period), and of promptly detecting and monitoring volcanic hotspots reducing false alarms.

Satellite remote sensing has been used to study and monitor volcanic activity for decades, thanks to many orbiting satellite platforms that provide a global coverage of active volcanoes with a high repetition frequency. Sensors like AVHRR (Advanced Very High Resolution Radiometer), aboard NOAA (National Oceanic and Atmospheric Administration), and MODIS (Moderate Resolution Imaging Spectrora- 
diometer) aboard EOS (Earth Observing System) satellites, have largely been used to detect and track volcanic ash plumes (e.g., Prata, 1989; Wen and Rose, 1994; Rose and Schneider, 1996; Ellrod and Connel, 1999; Krotkov et al., 1999; Mosher, 1999; Rose et al., 2000; Ellrod et al., 2003; Pergola et., 2004a; Bonfiglio et al., 2005; Pavolonis et al., 2006), and to study and monitor thermal volcanic activity (e.g., Harris et al., 1995, 1999, 2001, 2002; Wright et al., 2002a, 2004, 2005; Kaneko et al., 2002; Pergola et al., 2004b; Patrick et al., 2005) thanks to their features.

Most of the above mentioned satellite methods are generally based on spectral signatures that ash clouds and/or volcanic hotspots have in the mid and thermal infrared bands. Brightness temperature differences are often used to enhance thermal and ash features of volcanoes.

Specific indices have been proposed for ash cloud detection and tracking as well as for volcanic thermal anomaly monitoring. They have been tested and experimented studying many volcanic eruptions which have occurred in the world.

The split-window approach (e.g., Prata, 1989), one of the most widely used techniques for volcanic ash cloud detection, is based on the inverse absorption of thermal radiation from ash at 11 and $12 \mu \mathrm{m}$ compared to water vapour. The following index is computed to discriminate ash clouds

$$
T_{4}-T_{5}<0
$$

where $T_{4}$ and $T_{5}$ respectively represent the brightness temperatures measured in AVHRR channel 4 (centred around $11 \mu \mathrm{m}$ ) and 5 (centred around $12 \mu \mathrm{m})$.

Several studies enhanced the limits of such a technique in correctly detecting and discriminating volcanic clouds from water/ice clouds under specific observational/environmental conditions. As a possible improvement of such an approach Ellrod et al. (1999) proposed an index based on the use of an additional, the mid infrared, signal, described as

$$
B=C+m_{1}\left(T_{5}-T_{4}\right)+m_{2}\left(T_{3}-T_{4}\right)
$$

where $B$ is a brightness temperature $(\mathrm{K}), \mathrm{C}$ is a constant, $m_{1}$ and $m_{2}$ are scale factors and $T_{4}, T_{5}$ and $T_{3}$ (centred at around $3.5 \mu \mathrm{m}$ ) respectively represent the brightness temperatures measured in the TIR and MIR bands of AVHRR sensor. Since $B$ thresholds are generally difficult to choose to make the algorithm reliable and efficient under every atmospheric condition, a correct discrimination of volcanic ash plumes from meteorological clouds is not always possible.

Regarding volcanic hotspot detection and monitoring, several algorithms, generally based on the use of two different spectral bands, have been proposed.

The MODVOLC algorithm (Flynn et al., 2002; Wright et al., 2002a, 2004) uses an index named Normalised Thermal Index (NTI) to discriminate volcanic hotspots defined as

$$
N T I=\frac{R 22-R 32}{R 22+R 32}
$$

where $R 22$ and $R 32$ respectively represent the radiances measured in the MIR (band 22, 3.929-3.989 $\mu \mathrm{m}$ ) and TIR (band 32, 11.770$12.270 \mu \mathrm{m})$ channels of the MODIS sensor. This approach generally offers a reliable detection of hot volcanic features, even if a lack of sensitivity toward thermal anomalies of lower intensity may be observed because of the use of a fixed threshold on the MODIS images (Wright et al., 2004).

Other techniques have also shown a good capability in hotspot detection such as a contextual algorithm developed to monitor thermal activity over Japanese volcanoes (Kaneko et al., 2002). This approach recognizes pixels within a box located over a volcanic area as «anomalous» if

$$
\frac{\left(T_{3}-T_{4}\right)_{p i x e l}-\left\langle\left(T_{3}-T_{4}\right)\right\rangle}{\sigma_{\left(T_{3}-T_{4}\right)}}>3
$$

where $\left(T_{3}-T_{4}\right)_{\text {pixel }}$ is the difference between brightness temperatures measured in the AVHRR channel 3 and 4 for a pixel $(x, y)$, while $\left\langle\left(T_{3}-T_{4}\right)\right\rangle$ and $\sigma_{\left(T_{3}-T_{4}\right)}$ respectively represent the spatial mean and standard deviation calculated within a box of neighboring pixel.

Performances of these methodologies have already been fully assessed in several scientific papers, generally revealing a good capability in volcanic activity monitoring. However, it should 
be considered that some problems still remain, requiring specific improvements especially in terms of exportability in different geographic areas and under critical observational conditions.

Among the more recent satellite techniques developed for volcanic activity monitoring, a multi-temporal approach, named RST (Robust Satellite Techniques), has shown significant improvements in volcanic ash cloud detection and tracking (Di Bello et al., 2004; Pergola et al., 2001, 2004a; Filizzola et al., 2007), as well as in thermal anomalies monitoring compared to traditional techniques (Di Bello et al., 2004; Pergola et al., 2004b; Marchese et al., 2008).

This approach has been successfully used, together with advanced statistical methods, also to dynamically characterize thermal signals on Mt. Etna analyzing long time series of satellite products (Marchese et al., 2006; Lovallo et al., 2007a, 2007b). Recently, it has also been implemented in an automatic satellite monitoring system, developed at IMAA (Institute of Methodologies for Environmental Analysis) to monitor Italian volcanoes in near real-time using AVHRR data (Marchese et al., 2008). This system is capable of providing a prompt identification of anomalous hot volcanic surfaces both in their exact geographic location and relative intensity.

This paper presents some RST results obtained for the Mt. Etna eruptions of October 2002 and July 2006. The RST technique will also be implemented and analyzed on new geostationary satellites MSG-SEVIRI, especially in view of the development of a robust and efficient early warning system for volcanic hazard assessment and mitigation.

\section{Application of RST technique to volcanic activity monitoring}

As already widely described in previous papers (Tramutoli 1998, 2005; Di Bello et al. 2004; Pergola et al., 2004a,b) the RST approach considers every anomaly in space-time domain as a deviation from a «normal» state which is specific for each place and time of observation and which should be preliminarily determined. A perturbing event will be automati- cally identified as far as it is able to produce a significant deviation of the signal from its expected (i.e. under unperturbed conditions) value. The latter is formerly defined on the basis of a statistical analysis carried out on a long-term multi-temporal data set for each location $(x, y)$ of the satellite scene, computing a local variation index named ALICE (Absolute Llocal Index of Change Environment) as in the following:

$$
\otimes_{V}(x, y, t)=\frac{\left[V(x, y, t)-\mu_{V}(x, y)\right]}{\sigma_{V}(x, y)} .
$$

In eq. (2.1), $V(x, y, t)$ represents the satellite signal measured at time $t$ for each pixel $(x, y)$, while $\mu_{v}(x, y)$ and $\sigma_{v}(x, y)$ respectively represent the temporal mean (i.e. expected value) and the standard deviation (i.e. natural variability) of the signal. These terms are determined analyzing a long time series of homogenous satellite data, stratified according to some homogeneity criteria: same spectral channel, same period (e.g., month) and time (e.g., hour) of acquisition (Tramutoli et al., 1998, 2005). Therefore, the ALICE local variation index gives an estimation of how much the signal deviates from its normal behaviour, weighing this difference by the natural fluctuation that the signal normally undergoes, due to natural and observational noise factors. In this way, the higher the ALICE value (in modulus), the stronger the intensity of the detected anomaly.

\subsection{Volcanic ash cloud detection using AVHRR data}

To identify and track volcanic ash cloud using AVHRR data, the general formula reported in (2.1) is expressed as:

$$
\otimes_{\mathrm{D} T_{4-5}}(x, y, t)=\frac{\left[\Delta T_{4-5}(x, y, t)-\mu_{\mathrm{D} T_{4-5}}(x, y)\right]}{\sigma_{\mathrm{D} T_{4.5}}(x, y)}
$$

where $\Delta T_{4-5}(x, y, t)=B T_{11 \mu m}(x, y, t)-B T_{12 \mu m}(x, y, t)$ is the difference between the brightness temperatures measured in AVHRR channel 4 (centred at about $11 \mu \mathrm{m}$ ) and channel 5 (centred at about $12 \mu \mathrm{m})$, while $\mu_{\Delta T 4-5}(x, y)$ and $\sigma_{\Delta T 4-5}(x, y)$ respectively represent the temporal mean and standard 
deviation of $\Delta T_{4-5}(x, y, t)$ determined, as mentioned before, using a long-term time series of homogeneous satellite records (Di Bello et al., 2004; Pergola et al., 2004a; Filizzola et al., 2007).

This differential approach takes into account the reverse behaviour of ash cloud at wavelengths of $11 \mu \mathrm{m}$ and $12 \mu \mathrm{m}$ compared to meteorological clouds, mainly due to acid components and ash particles (Prata, 1989).

Considering that even the difference between the brightness temperature measured in AVHRR channel 3 (centred around $3.5 \mu \mathrm{m}$ ) and channel 4 may further indicate the possible presence of volcanic ash (Ellrod and Connel, 1999) in the atmosphere, another index may also be computed and has been proposed within the RST framework

$$
\otimes_{\mathrm{D} T_{3-4}}(x, y, t)=\frac{\left[\Delta T_{3-4}(x, y, t)-\mu_{\mathrm{DT}_{3-4}}(x, y)\right]}{\sigma_{\mathrm{D} T_{3-4}}(x, y)}
$$

where $\Delta T_{3-4}=B T_{3.5 \mu m}-B T_{11 \mu m}$, is the difference between the brightness temperatures measured in AVHRR channel 3 (at $3.5 \mu \mathrm{m}$ ) and channel 4 (at $11 \mu \mathrm{m}$ ), while $\mu_{\Delta T_{3-4}}(x, y)$ and $\sigma_{\Delta T_{3-4}}(x, y)$ still have the meaning of the «reference» signals.

The combination of both indexes leads to a so-called «three-channel» RST approach (Filizzola et al., 2007), where $\otimes_{\Delta T 4-5}(x, y, t)$ and $\otimes_{\Delta T 3-4}$ $(x, y, t)$ should respectively assume negative and positive values in the presence of ash clouds. A decrease of $\Delta T_{4-5}$ is expected, in fact, in the presence of volcanic plumes due to the reverse absorption of ash compared to atmospheric water vapour, in spite of an increase of $\Delta T_{3-4}$ that should assume a different intensity, depending on observational conditions (e.g., night/day). As described in Filizzola et al. (2007), the RST approach used in its three channel configuration further improves its capability in correctly detecting and tracking volcanic ash clouds, compared to a simplified «two-channel» configuration. Even if the latter assures good reliability in ash plume discrimination, it may be better employed to infer ash cloud properties and characteristics such as the ash relative content within the plume (Filizzola et al., 2007).

\subsection{Volcanic thermal anomalies detection using AVHRR data}

To detect and monitor volcanic thermal anomalies using AVHRR data, the MIR channel (band 3: 3.55-3.93 $\mu \mathrm{m}$ ) of this sensor is processed, and the local variation index described in (2.1) is expressed as:

$\otimes_{\text {MIR }}(x, y, t)=\frac{\left[T_{\text {MIR }}(x, y, t)-\mu_{\text {MIR }}(x, y)\right]}{\sigma_{\text {MIR }}(x, y)}$

In this expression, $T_{M I R}(x, y, t)$ represents the thermal signal (i.e. the brightness temperature) acquired at time $t$ for pixel $(x, y)$, while $\mu_{M I R}(x, y)$ and $s_{M I R}(x, y)$ still represent, respectively, temporal average and standard deviation obtained for the same location $(x, y)$, following RST prescriptions.

Higher $\otimes_{M I R}(x, y, t)$ values generally indicate thermal anomalies of higher intensity and/or hotspots of large extension. Different levels of the same index may also be used to identify possible thermal anomalies of different intensity, without producing significant reductions of RST reliability (Pergola et al., 2004b). As shown in previous studies, the RST approach may be successfully used in any atmospheric and observational condition (e.g. day/night, winter/summer). Even in daytime and in summer seasons when the probability of false occurrences is higher, the proposed approach is, in fact, capable of strongly limiting the false alarm rate (Marchese et al., 2008). Moreover, thanks to its sensitivity, anomalous thermal signals of lower intensity, that may sometimes preannounce impending eruption, may be potentially detected by RST as well (Di Bello et al., 2004; Pergola et al., 2004b).

\subsubsection{Thermal anomaly detection using SE- VIRI data: application for early warning purposes}

Several studies have shown that geostationary satellites such as GOES, thanks to their high repetition frequency which allows continuous observation over the target areas, should be the most suitable to monitor volcanoes from space (e.g., Harris and Thornber 1999). 
SEVIRI sensor has been aboard MSG (Meteosat Second Generation) satellites since 2002. It offers an unique opportunity to monitor volcanoes in real time due to the best temporal resolution (15 $\mathrm{min})$ today available, a channel in the MIR spectral band (centred at $3.9 \mu \mathrm{m}$ ), and a spatial resolution of about $4 \mathrm{~km}$.

SEVIRI 15-minute repetition rate offers the possibility of better characterizing MIR thermal signals with a higher temporal sampling than AVHRR, significantly reducing the observational noise.

In fact, for the AVHRR sensor flying aboard NOAA - Polar Orbiting Environmental Satellite with sun-synchronous attitude, residual deviation in the time of overpass, from one orbit to another, still remain. They produce a residual level of observational noise, also as far as homogeneous data sets are considered. On the other hand, the geostationary attitude of SEVIRI, allows us to receive images always at the same (exact) hour of the day reducing noise related to variations of illumination condition. Moreover, thanks to a better (natural) co-location of satellite images and to an invariant viewing geometry, that reduce observational noise further, improvements in RST sensitivity are also expected even in spite of a lower spatial resolution compared to AVHRR (1 km).

To detect and monitor volcanic thermal anomalies using SEVIRI, the MIR channel of this sensor is processed and the local variation index (ALICE) is still computed as in (2.4).

The first implementation of RST on SEVIRI records was successfully tested during the 2004-2005 Mt. Etna eruption (Marchese et al., 2008). Preliminary results showed, as expected, an increased sensitivity in detecting low level signals, a high capability in monitoring the eruption evolution and, more importantly, a high potential in promptly identifying sudden thermal changes related to unexpected volcanic activity.

Moreover, in order to further investigate such a potential of RST on SEVIRI, to promptly identify the beginning of new eruptive events, possibly related to sudden and abrupt changes in thermal signals, a differential index may also be proposed and computed following RST prescriptions. In particular, considering the SEVIRI MIR signal acquired at time $t_{1}$ and at time $t_{0}$, and similarly comparing the time difference $\Delta T_{M I R}(x, y, \Delta t)=T_{M I R}\left(x, y, t_{1}\right)-T_{M I R}\left(x, y, t_{0}\right)$ with the temporal mean $\mu_{M I R}(x, y, \Delta t)$ and standard deviation $\sigma_{M I R}(x, y, \Delta t)$ observed at the same time slots $\left(\Delta t=t_{1}-t_{0}=15 \mathrm{~min}\right)$, a differential index may be computed, at pixel level, as

$$
\otimes_{M I R}(x, y, \Delta t)=\frac{\left[\Delta T_{M I R}(x, y, \Delta t)-\mu_{M I R}(x, y, \Delta t)\right]}{\sigma_{M I R}(x, y, \Delta t)}
$$

The opportunity offered by the high temporal resolution of SEVIRI, together with the robustness and the reliability demonstrated by the RST approach, should both contribute to develop an efficient satellite system, which may allow us to improve our capabilities in volcanic activity monitoring.

The following section shows and discusses some recent RST results for volcanic ash plumes and thermal anomaly detection and monitoring. In particular, the potential of such an approach in early warning and operational monitoring will be analyzed. Preliminary results of the first application of the above defined RST differential index in time domain will also be reported.

\section{Results}

\subsection{Volcanic ash cloud monitoring}

On 26 October 2002, after a semi quiescence phase, a vigorous lateral eruption occurred at Mt. Etna (37.73N, 15.00E, Sicily, Italy), ejecting an enormous volume of volcanic ash into the atmosphere that covered hundreds of kilometres along the Sicilian coasts (INGV 2002).

On 27 October, a thick black cloud rose about $2100 \mathrm{~km}$ (Carn et al., 2005) above the vents on the upper southern flank, and smaller ash columns rose from the vents located on the northeast Rift (Bertrand et al., 2003). This plume was southward directed and moved towards Catania city reaching Mount Iblei area (INGV, 2002). A few days later, some towns (Catania, Nicolosi, Mascalucia, San Pietro 


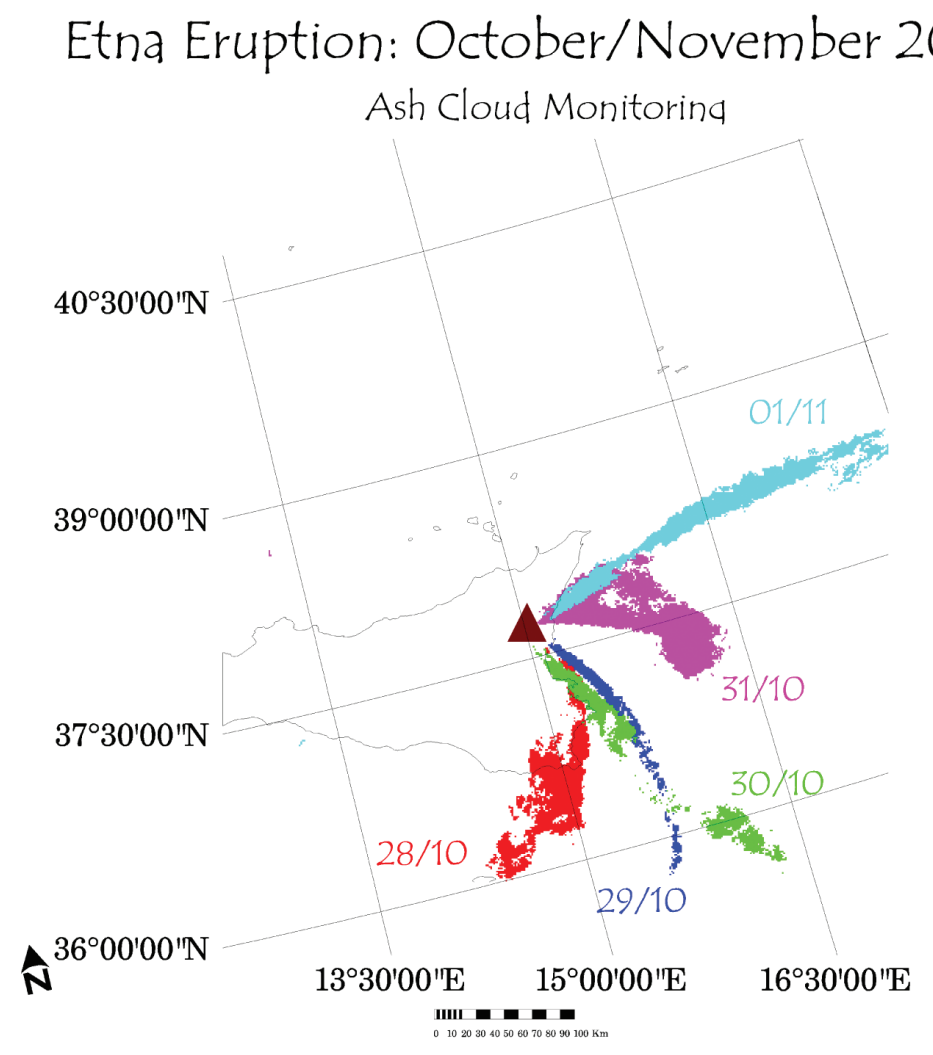

Fig. 1. Map of Mt. Etna ash clouds detected by RST using a three-channel configuration approach during the period 28 October-1 November 2002. Ash plumes identified on AVHRR images have been reported in different colours on the map according to the corresponding day.

Clarenza, Gravina, Pedara and Trecastagni) located in the Mt. Etna area were strongly affected by the ash fallout. It reached the city of Syracuse, about $80 \mathrm{~km}$ away from the eruptive centres (INGV, 2002). Ash emissions continued for several days forcing the closure of the «Fontanarossa» Catania's International Airport on 29, 30 and 31 October (INGV, 2002).

The Mt. Etna eruption of October 2002 was already analyzed by RST, that also showed, in comparison with a traditional split window technique, a high potential in correctly identifying and tracking volcanic ash plume, both using a two-channel and a three-channel configuration approach (Filizzola et al., 2007). Here, a demonstration of the monitoring capabilities achievable with such an approach is shown. Figure 1 reports the space-time evolution of the Mt. Etna ash plume, emitted between 28 October 2002 and 1 November 2002 and detected by RST.

The same figure shows the ash dispersion area and highlights a continuous (daily) movement of the volcanic ash cloud from a southeast to northeast direction. These observations were in accordance with direct measurements carried out using LIDAR systems that identified the Mt. Etna ash many kilometres away from the Sicilian coast, in the southern regions of continental Italy on the first days of November (Pappalardo et al., 2004). The daily ash dispersion maps reported in fig. 1 , were automatically ob- 
tained by applying the RST approach in its three-channel configuration (Filizzola et al., 2007) on AVHRR data directly received by our own HRPT station. They were available in standard and geolocated formats within minutes after raw data acquisition. Therefore, the timely provision of such information and its continuous (e.g. daily, but up to 6-hourly) updating, may provide useful information to better guarantee aviation safety. In particular, the further implementation of this technique on high temporal resolution sensors, such as SEVIRI, might significantly improve our ash cloud monitoring capabilities up to a real-time updating and provision, as required by an operational scenario. In this case, the possible impact of the coarser SEVIRI spatial resolution should be addressed.

\subsection{Thermal anomaly detection and monitoring}

Between 23:30 and 24:00 local time of 14 July 2006, a new lateral eruption occurred at
Mt. Etna, with the opening of an eruptive fissure on the east flank of the SE Crater (INGV 2006).

Two eruptive vents, respectively located at about $3100 \mathrm{~m}$ and $3000 \mathrm{~m}$ altitude, emitted a lava flow toward Valle del Bove, while a moderate strombolian activity, from the East flank of the SE Crater, produced a small amount of ash fall on Catania city (INGV 2006).

This eruption was automatically recognized by the satellite volcano monitoring system developed at IMAA, as shown by two thermal anomalies, having $\otimes_{M I R}(x, y, t)>3$, detected over Mt. Etna area on the AVHRR night-time pass of 15 July 2006 at 02:46 local time. They were identified about three hours after the beginning of the new eruptive event. These thermal anomalies, reprojected on a geographic map of Mt. Etna, were correctly located within the area affected by lava flows. No other hotspot was flagged elsewhere, showing the high reliability of RST (fig. 2).

The eruption of Mt. Etna of July 2006 was also analyzed using SEVIRI MIR data, directly
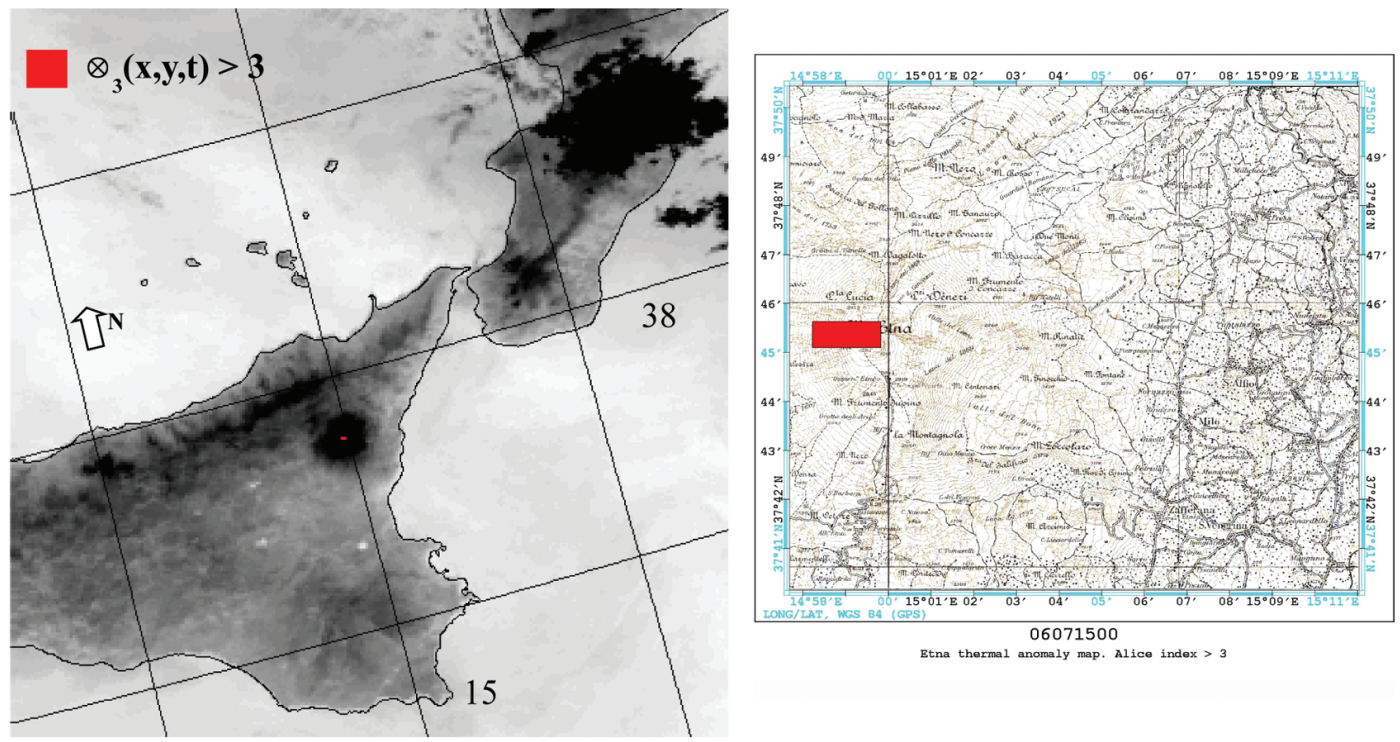

Fig. 2. AVHRR MIR data of 15 July at 02:46 Local Time processed by RST. Thermal anomalies detected over Mt. Etna, having $\otimes_{M I R}(x, y, t)>3$, have been reported in red. On the right side, thermal anomalies automatically reprojected on Mt. Etna geographic map are shown. 

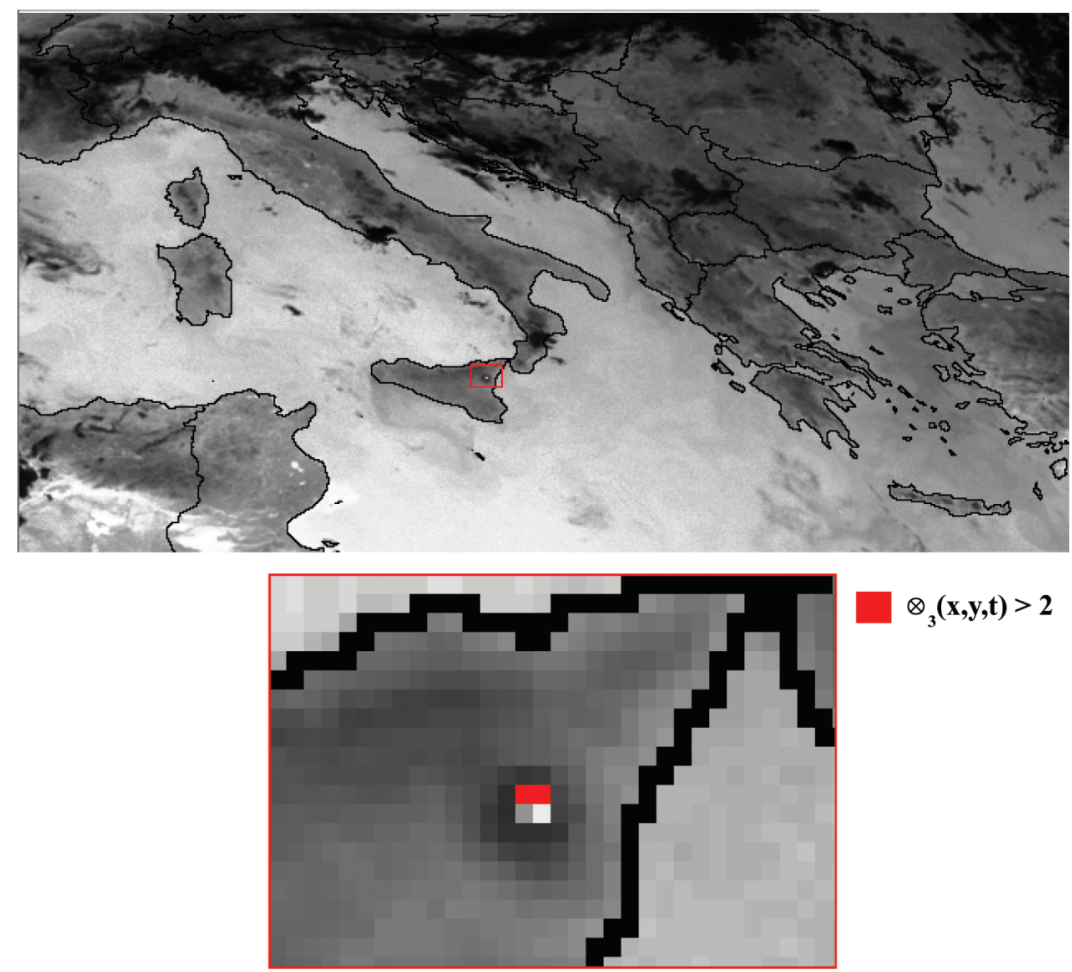

$\otimes_{3}(\mathbf{x}, \mathbf{y}, \mathbf{t})>2$

Fig. 3. SEVIRI MIR data of 15 July at 02:00 Local Time processed by RST. Thermal anomalies detected over Mt. Etna, having $\otimes_{M I R}(x, y, t)>2$, are reported in red.

acquired at DIFA (Department of Engineering and Physics of the Environment) of University of Basilicata. Computing the local variation index following its standard configuration, some thermal anomalies having $\otimes_{M I R}(x, y, t)>2$ were detected over Mt. Etna, starting from 15 July 2006 at 02:00 local time (fig. 3). These hotspots were therefore flagged about two hours after the onset of the eruptive event, and less than one hour before its observation with the AVHRR RST product. Moreover, it should be noted how, also in this case, no false identification was marked by RST all over the scene, confirming the reliability of such an approach, regardless of the specific satellite/ sensor system where it is implemented (RST exportability).

To study the time dynamics of the eruptive event and to assess the actual potential of the proposed approach in identifying possible early time signature of the eruption, an accurate analysis of the satellite signal in time domain has been performed. A similar statistical analysis was carried out by different authors to exploit the thermal radiance of $10 \times 10$ GOES subscene centered on Popocatépetl's (Mexico) summit, for lava dome detection (Wright et al., $2002 \mathrm{~b}$ ). In particular, the daily curve of the brightness temperature measured in SEVIRI MIR channel, for the pixel covering Mt. Etna, has been studied analyzing the day of the eruption (14 July) and two unperturbed days in the same period (3 and 4 July). The latter were investigated because they were characterised by no/scarce clouds over the target area and by the absence of any volcanic activity. Figure 4 reports the above mentioned curves, obtained by considering all 96 daily measures (one every 15 


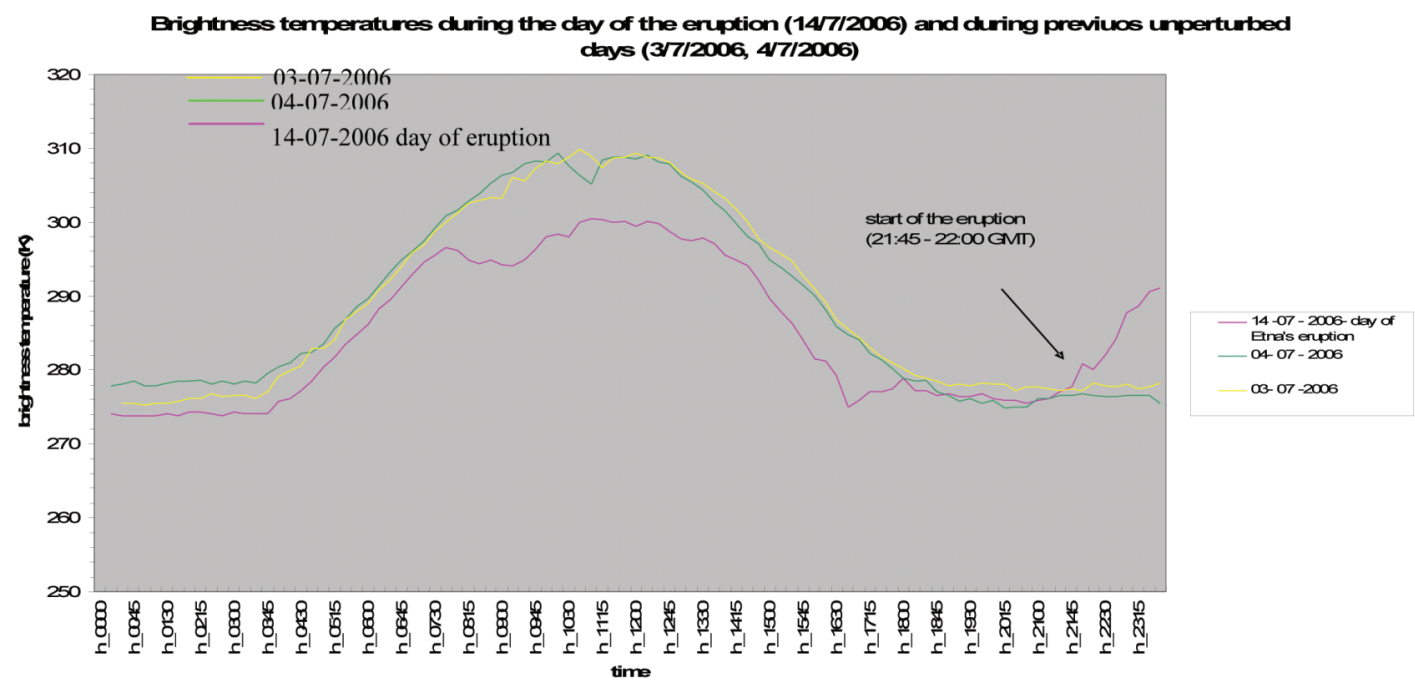

Fig. 4. Daily curves of the brightness temperatures measured in the SEVIRI MIR channel during two unperturbed days ( 3 and 4 July 2006) are reported, respectively, in yellow and green colours on the plot, and during the day of the eruption (14 July 2006) coloured in purple.
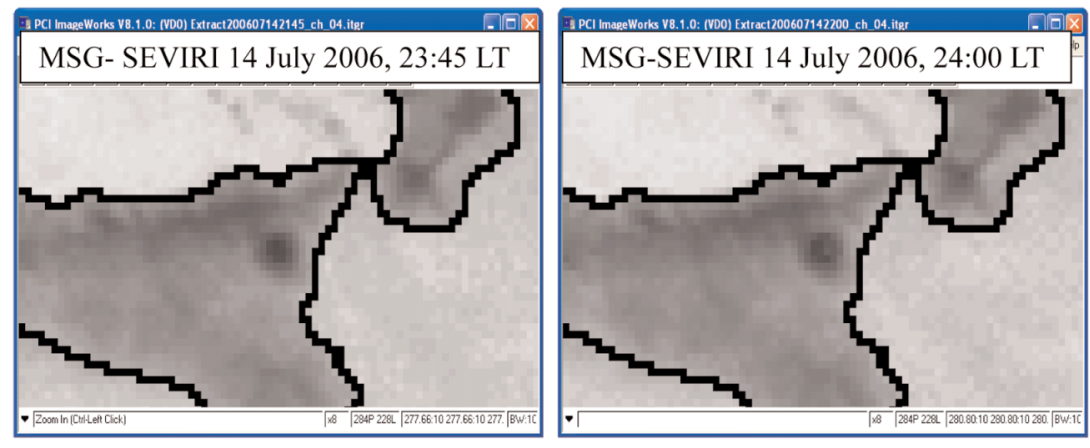

Low

High

Fig. 5. SEVIRI MIR images of 14 July 2006 received at 23:45 (on the left) and at 24:00 (on the right side). Brightness temperature values are depicted in grey scale: higher the value brighter the grey tone.

min) of the satellite sensor. As shown in this figure, all curves have a similar trend following, as expected, the solar daily cycle, and reaching their relative maximum value around local noon. A slight difference in relative intensity between 14 July and the two unperturbed days is evident, due to a thin cloud passage over the area during the hours preceding the eruption. This thin cloud presence prevents the sun from warming the earth and atmosphere. Under these conditions, the brightness temperatures measured at the sensor are generally lower. However, at approximately 18:00 GMT (i.e. 20:00 LT) the cloud effect completely disappears, and the 
three curves come back to follow the same tendency, without showing significant differences for more than three hours (see the purple, yellow and green lines on the figure between 18:00 and 21:30 GMT). On the other hand, between 21:45 and 22:00 GMT (i.e. 23:45-24:00 LT) an abrupt change in the temporal trend of the purple line (the one describing the day of the eruption) is clearly visible. Therefore, for the following hours, the increase in the signal becomes more evident and intense, due to the first emission of lava flows. In particular, after 22:00 GMT the deviation of the purple lines from the two others appears clean evident. The thermal signal of 14 July significantly increases up to $290 \mathrm{~K}$ whereas the signals measured on unperturbed days remain almost constant at $275 \mathrm{~K}$. It should be stressed here that, during the first minutes after the onset of the eruptive event (i.e. between 21:45 and 22:00 GMT) the increasing signal, although evident, might not be significant as far as absolute values are simply considered. The magnitude of the increasing signal may be comparable, in fact, to a natural fluctuation of the signal due to changes in observational/illumination conditions. The confirmation of this circumstance is proven by two SEVIRI images, received at 21:45 GMT and 22:00 GMT and shown in fig. 5, where no evidence of a significant increasing signal over Mt. Etna is detectable in terms of measured brightness temperature. Therefore a change in time trend, with a clear abrupt slope inversion of the curve is the actual time signature of an anomalous and unexpected signal occurrence.

In order to enhance such an effect, the above defined differential RST index was applied here for the first time. The daily trend of $\Delta T_{M I R}$ $(x, y, \Delta t)=T_{M I R}\left(x, y, t_{i+1}\right)-T_{M I R}\left(x, y, t_{i}\right)\left(\right.$ with $t_{i+1}>$ $t_{i}$ ) was analyzed for the eruption day (i.e. $14 \mathrm{Ju}-$ ly), considering the brightness temperatures measured on the same pixel in contiguous time slots, with a 15 min time step (i.e. $t_{i+1}-t_{i}=15$ min). Figure 6 reports the $\Delta T_{M I R}(x, y, \Delta t)$ quantity, together with the previous plotted curve of the absolute brightness temperature $\left(T_{M I R}\right)$. As

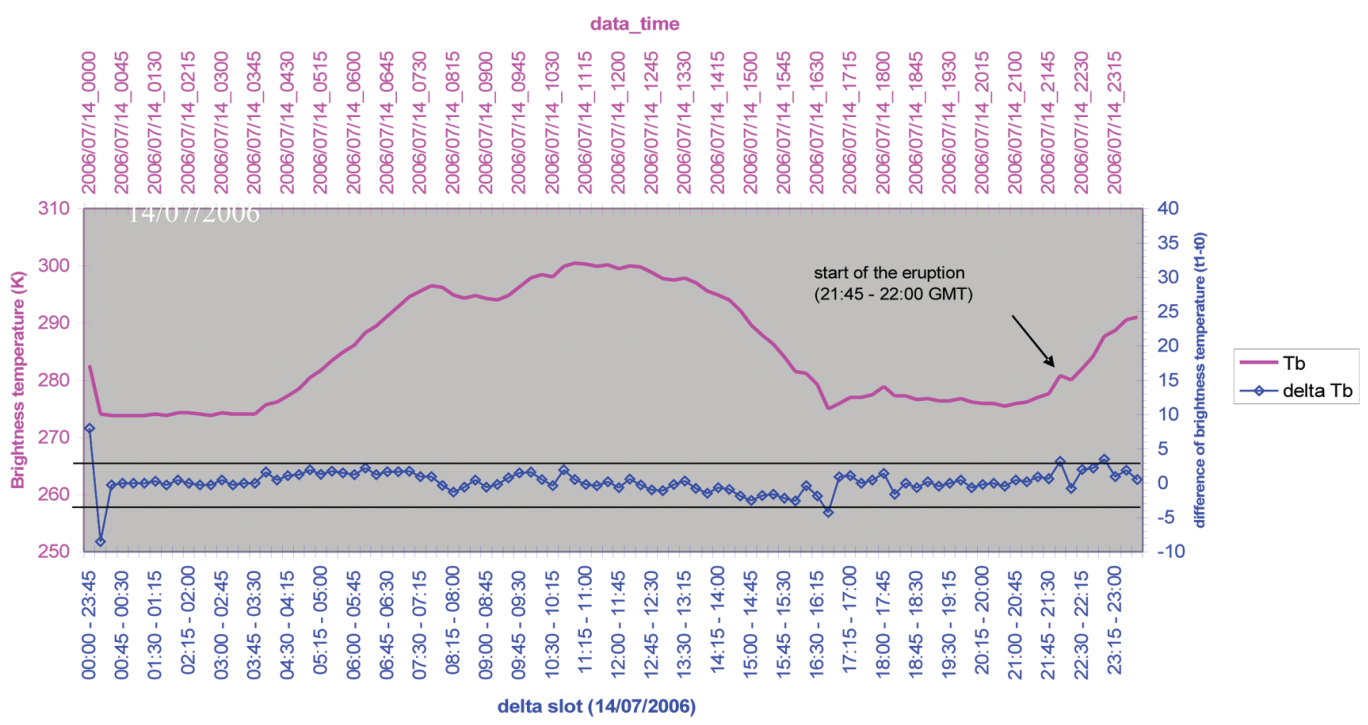

Fig. 6. Daily curves of the brightness temperatures measured in the SEVIRI MIR channel (purple colour on the plot), and of the difference of the MIR thermal signal measured in two contiguous time slots (in blue), with a 15 minute step, during 14 July 2006 (see text). Vertical axes report, on the left, the absolute brightness temperature in MIR channel and, on the right, the difference of brightness temperatures observed in two contiguous time slots 15 min apart from each other. 


\section{Tb \& deltaTb (03/07/2006)}

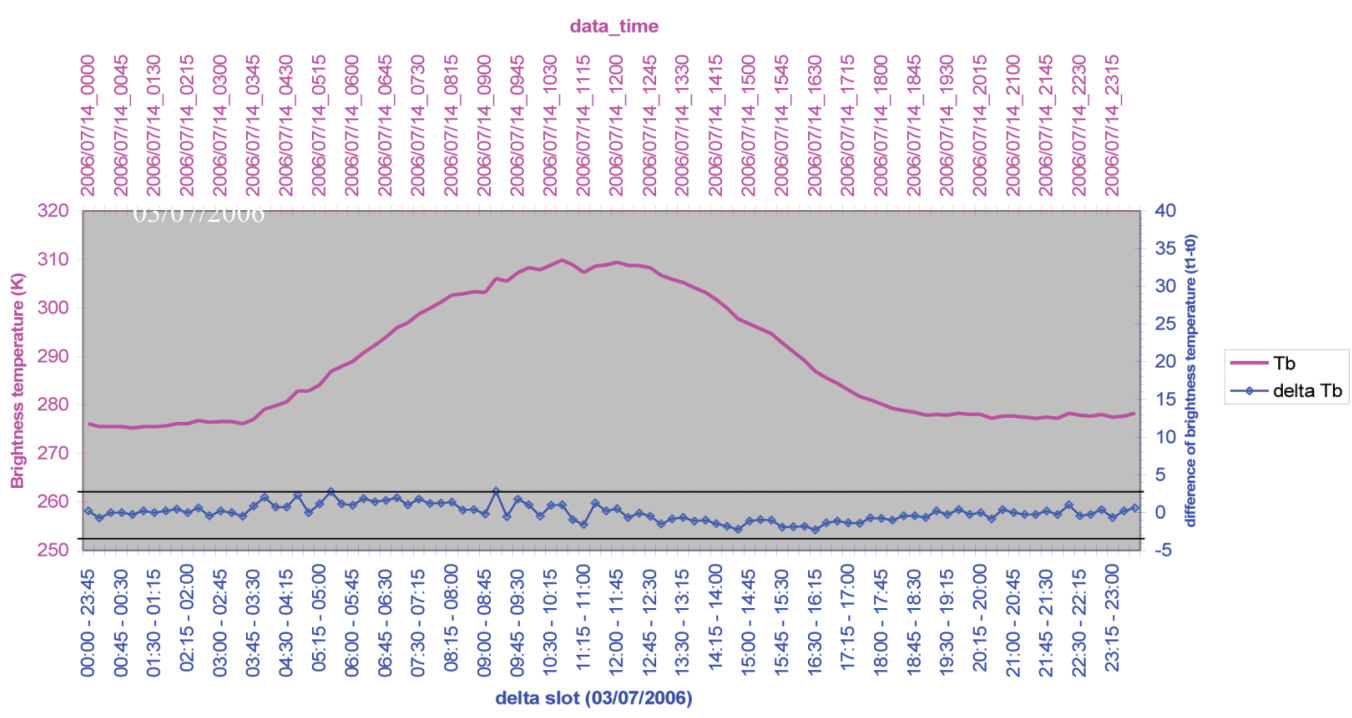

Tb \& deltaTb (04/07/2006)

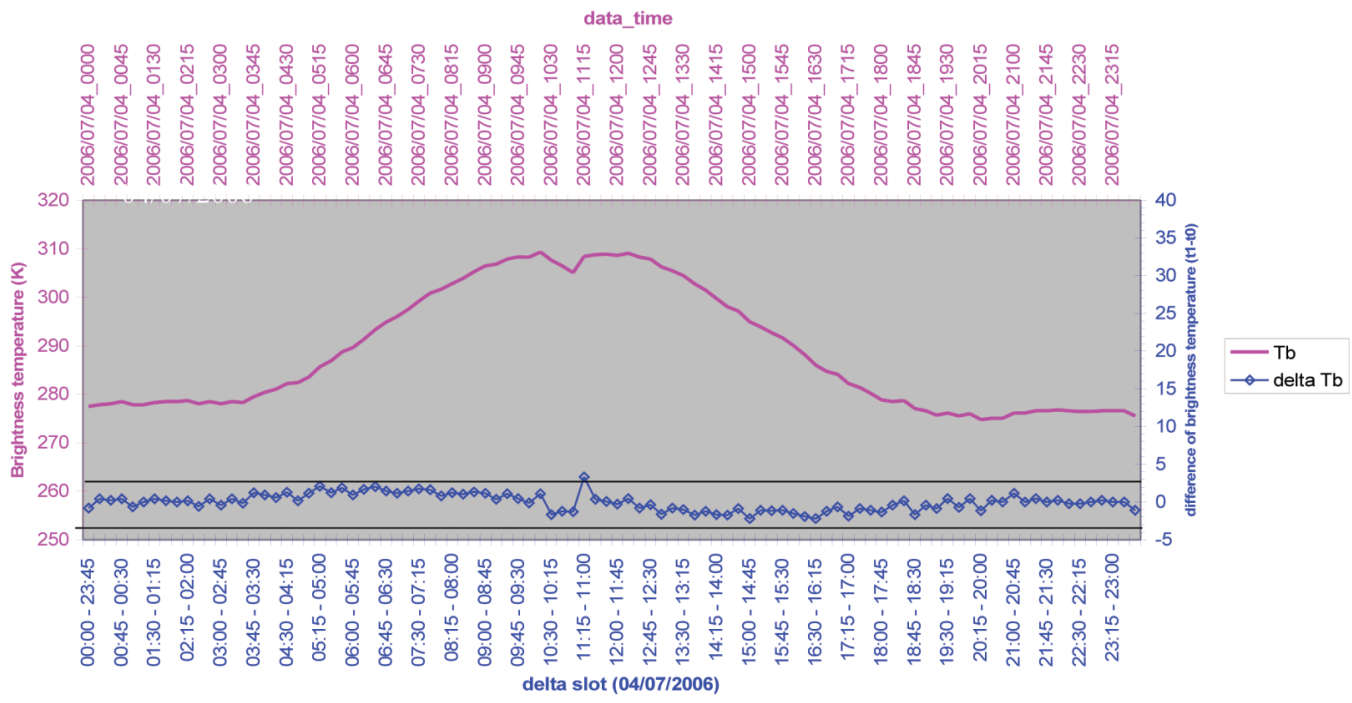

Fig. 7. As fig. 6, but for 3 July (top) and 4 July (bottom).

can be seen from this figure, the differential signal (depicted in blue) is quite a flat curve, with natural (statistical) fluctuations generally confined between $-3 \mathrm{~K}$ and $+3 \mathrm{~K}$. This sort of invariance is mainly due to the very short time step between one measure and another (15 min), when natural induced changes in brightness temperatures are typically very small. Val- 


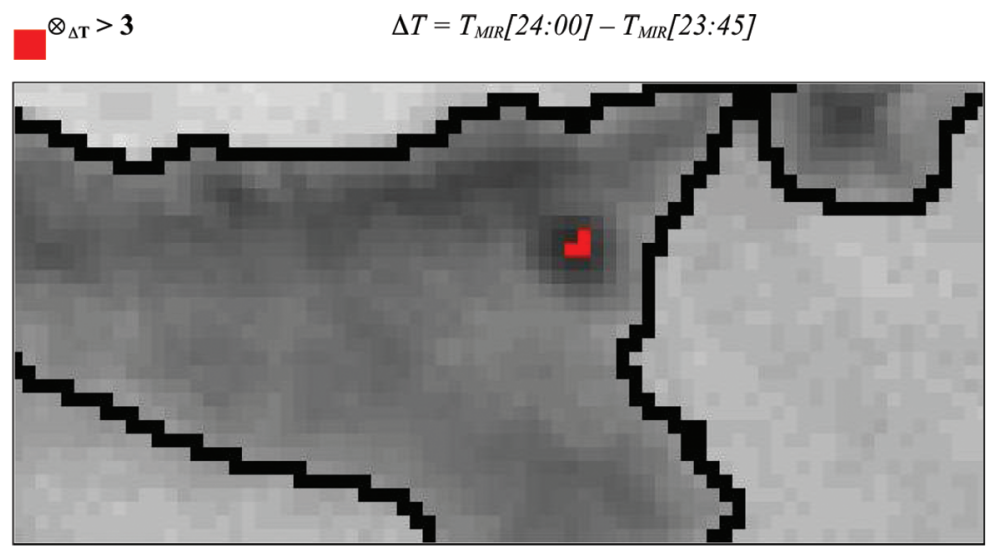

Fig. 8. Locations of thermal anomalies (with ALICE > 3) detected by SEVIRI MIR data applying the differential RST approach (see text).

ues of $\Delta T_{M I R}(x, y, \Delta t)$ that significantly exceed this threshold (i.e. $\left|\Delta T_{M I R}(x, y, \Delta t)\right|>3$ ) were only observed in the case of meteorological cloud that moved toward the analyzed pixel (determining very low, negative $\Delta T_{M I R}(x, y, \Delta t)$ values), and in the time interval between $21: 45$ and $22: 00$ GMT (23:45 and 24:00 Local time), exactly when the new eruptive event occurred (fig. 6).

In particular, the only strong positive difference, which simply means a significant increase in the thermal signal which occurred in a short time period, is observed at the eruption onset.

This result corroborates the potential of such an indicator to promptly (i.e. within minutes) identify thermal changes induced by unexpected volcano re-activation and is mainly due to the pronounced invariance naturally shown by the differential signal under unperturbed conditions.

This circumstance, in fact, obviously enhances the capability of the proposed technique to reliably detect changes which, although relatively weak, may be related to anomalous and unexpected events. To better validate the previous result, a similar analysis was carried out on the two previously shown unperturbed days (i.e. 3 and 4 July). Figure 7 reports the two plots of $\otimes T_{M I R}(x, y, \Delta t)$ (in blue) and absolute brightness temperature values (in pink) for both days. Looking at the figure it can be noted that: i) for 3 July, no outliers (i.e. $\left|\Delta T_{M I R}(x, y, \Delta t)\right|>3$ ) were observed during the whole day, confirming that no abrupt changes in thermal signal occurred; ii) on the other hand, on 4 July a single outlier was observed between 11:00 and 11:15 GMT, where the $\Delta T_{M I R}$ signal reached the value of $3.3 \mathrm{~K}$. This anomalous signal is clearly related to an abrupt slope variation of the brightness temperature curve due to a previous decrease of the signal probably related to a thin cloud passage. Therefore, applying a robust cloud detection procedure this signal could be identified and removed, allowing the short-term $\Delta T_{M I R}$ variable to correctly discriminate only the signal changes related to actual volcanic thermal anomalies.

The high potential of the differential approach is confirmed by the application of the RST scheme to the $\Delta T_{M I R}(x, y, \Delta t)$ quantity. Computing the local variation index in its differential configuration, as already described in (2.1), three hotspots, having $\otimes_{M I R}(x, y, \Delta t)>3$, were then flagged over Mt. Etna at 24:00LT, just in correspondence to the time of the new eruptive event onset (fig. 8). Therefore, an automatic warning system based on this technique, would have been able to recognize (and to re- 
port) a thermal change on the volcano within minutes from its actual occurrence.

As an additional advantage of this differential RST scheme, the improved achievable sensitivity was stressed. In this new configuration three anomalous pixels having a higher level of intensity were identified, in comparison with the two detected using RST in standard configuration

This result confirms the RST potential in promptly identifying automatically abrupt anomalous changes in thermal signals, related to the beginning of new eruptive events. In this case a differential local variation index should be used, in spite of a standard ALICE index, which is more useful to monitor thermal volcanic activity after the early stages of the eruption.

The better sensitivity (higher signal-tonoise ratio) of RST on new geostationary satellites, together with the very high temporal resolution of SEVIRI, provides a high potential to monitor volcanic activity in real time. It represents a starting point toward a definition of an efficient and reliable satellite early warning system for volcanic hazard mitigation.

\section{Conclusions}

This paper assessed the RST capability for volcanic ash plume detection and tracking, and for hotspot identification and monitoring.

Results obtained analyzing the Mt. Etna eruption of October 2002 have shown that volcanic ash clouds may be successfully tracked by RST, that may provide a reliable identification of the ash dispersion area in a continuous manner. This approach seems to be particularly suitable for operationally monitoring volcanic ash plumes in highly risky areas, contributing to improve aviation safety.

The more recent Mt. Etna eruption of July 2006 was also analysed by the proposed approach processing AVHRR MIR data directly acquired at IMAA. In this case, volcanic thermal anomalies related to a lava effusion that occurred from a new fissure which opened on the flank of the volcano were correctly detected on the first AVHRR data which was acquired about three hours after the eruption onset. These hotspots were automatically flagged by the volcano monitoring system developed at IMAA, and were identified both in their correct geographic location and relative intensity.

In order to assess RST capabilities and its potential for early warning and rapid alert purposes, the Mt. Etna eruption of July 2006 was also analyzed processing SEVIRI MIR data, which allow a 15-min repetition rate, and computing both a standard and a first proposed differential local variation index.

In the first case, volcanic thermal anomalies were identified over Mt. Etna about two hours after the occurrence of the actual event. This demonstrated that in spite of a lower spatial resolution than AVHRR sensor, SEVIRI may further improve RST capability in volcanic thermal anomaly detection and monitoring, thanks to a better signal-to-noise ratio and a higher observational frequency. With such an indicator the first detection of volcanic thermal anomalies occurred about one hour earlier than the AVHRR warning.

The definition and computation of a differential local variation index, which compares the difference between the MIR brightness temperatures acquired in two contiguous time slots with a 15 min step, with its normal behaviour, seems to be more suitable to promptly identify the beginning of new eruptive events. A sudden increase in MIR thermal signal, related to a new lava effusion, occurred over Mt. Etna between 23:45 and 24:00 local time of 14 July 2006, was in fact successfully and promptly identified by this innovative RST differential scheme.

The warning, using this original RST configuration, was reported at 24:00 LT as a coeruptive warning, about two hours before the first signal detectable with the traditional RST scheme. Moreover, the early detection with such RST differential scheme, was achieved with an improved level of sensitivity both in terms of number of pixels flagged as anomalous and of intensity of anomalies. Therefore, this result seems to suggest that the advantages posed by the high observational frequency of SEVIRI may compensate the possible drawbacks due to its coarse $(3-4 \mathrm{~km})$ spatial resolution. This allows us to achieve a good sensitiv- 
ity to detect abrupt anomalous changes in thermal signals related to new eruptive events. Even if these preliminary results need further investigation, the high potential of the RST scheme for volcanic activity monitoring in real-time is highlighted. This potential is very important in view of a satellite early warning system for volcanic hazard assessment and mitigation.

\section{Acknowledgements}

This work has been partially funded by the Italian Department of Civil Protection in the frame of the 2004-2006 Agreement with Istituto Nazionale di Geofisica and Vulcanologia INGV.

\section{REFERENCES}

Bertrand, C., N. Clerbaux, A. Ipe and L. Gonzalez (2003): Estimation of the 2002 Mt. Etna eruption cloud radiative forcing from Meteosat-7 data, Remote Sensing Environ., 87, 257-272.

Bonfiglio, A., M. Macchiato, N. Pergola, C. PietraperTOSA and V. TRAMUTOLI (2005): AVHRR automated detection of volcanic clouds, Inter. J. Remote Sensing., 26 (1), 9-27.

Carn, S., A. Strow, L.L. De Souza-Machado, S. EdMONDS and Y. HANNON (2005): Quantifying tropospheric volcanic emissions with AIRS. The 2002 eruption of Mt. Etna (Italy), Geophys. Res. Lett., 32, L02301, doi: 10.1029/2004GL021034.

Casadevall, T.J. (1994). The 1989-1990 eruption of Redoubt Volcano, Alaska; impacts on aircraft operations. J. Volcanol.Geotherm. Res., 62, 301-31.

Di Bello, G., C. Filizzola, T. Lacava, F. Marchese, N. Pergola and C. Pietrapertosa (2004): Robust satellite techniques for volcanic and seismic hazards monitoring, Ann.Geophysics, 47(1), 49-64.

Ellrod, G.P. and B.H. ConNel (1999): Improvements in volcanic ash detection using GOES multispectral image data, in 8th Conference on Aviation, Range, and Aerospace Meteorology (American Meteorological Society Preprint volume), 326-329.

Ellrod, G. P., B.H. Connel and D.W. Hillger, (2003): Improved detection of airborne volcanic ash using multi-spectral infrared satellite data, J. Geophys. Res., 108 (D12), 4356, doi: 10.1029/2002JD002802.

Flynn, L.P., R. Wright, H. Garbeil, A.J.L. Harris and E. PILGER (2002): A global thermal alert using MODIS: initial results from 2000-2001, Adv. Environ. Monitoring Modeling, 1, 5-36.

Filizzola, C., T. Lacava, F. Marchese, N. Pergola, I. SCAFFIDI and V. TRAMUtoli (2007): Assessing RAT (Robust AVHRR Technique) performances for volcanic ash cloud detection and monitoring in near real-time: The
2002 eruption of Mt. Etna (Italy), Remote Sensing Environ., 107, 3, 440-454. doi: 10.1016/j.rse.2006.09.020.

Harris, A.J., S.E.J. Swabey and J. Higgins (1995): Automated threshold of active lava using AVHRR data. Inter. J.Remote Sensing, 16 (18), 3681-3686.

HARRIS, A.J., R. Wright and L.P. FlynN (1999): Remote monitoring of Mount Erebus volcano, Antarctica, using polar orbiters: progress and prospect, Inter. J. Remote sensing, 20, 15 and 16, 3051-3071.

Harris, A.J.L. and C.R. Thornber (1999): Complex effusive events at Kilauea as documented by the GOES satellite and remote video cameras, Bull. Volcanol., 61, 382-395

Harris, A.J., E. Pilger, L.P. Flynn, H. Garbeil, P.J. Mouginis-Mark, J. Kauahikaua and C. Thorber (2001). Automated high temporal resolution thermal analysis of Kilauea volcano, Hawai'i, Using GOES satellite data, Inter. J. Remote Sensing, 22 (6), 945-967.

HARris, A.J., E. PILGER and L.P. FlynN (2002): Web-Based Hot Spot Monitoring using GOES: What it is and How it Works, Adv. Environ. Monitoring Modelling, 1 (3), 5-36.

INGV (2002-2006), Available at web site: http://www.ct.ingv.it/.

Kaneko, T., A. Yasuda, T. Ishimaru, M. TAkagi, M.J. Wooster and T. KAgIYAMA (2002): Satellite hot spot monitoring of Japanese volcanoes: a prototype AVHRR based, Adv. Environ. Monitoring Modelling, 1 (1), 125-133.

Krotkov, N.A., O. Torres, C. Seftor, A.J. Krueger, A. KOSTINSKI and W.I. Rose (1999): Comparison of TOMS and AVHRR volcanic ash retrievals 726 from the August 1992 eruption of Mt. Spurr, Geophys. Res. Lett., 26(4), 455-458.

Lovallo, M., F. Marchese, N. Pergola and L. Telesca (2007a). Fisher Information Measure of temporal fluctuations in satellite advanced very high resolution radiometer thermal signals recorded in the volcanic area of Etna (Italy), Communications in Nonlinear Science and $\mathrm{Nu}$ merical Simulation, doi: 10.1016/j.cnsns.2007.07.006.

Lovallo, M., F. Marchese, N. Pergola and L. Telesca (2007b): Fisher information analysis of volcano-related Advanced Very High Resolution Radiometer (AVHRR) thermal products time series, Physica A, 384, 529-534. doi: 10.1016/j.physa.2007.05.066.

Marchese, F., N. Pergola and L. Telesca (2006): Investigating the temporal fluctuations in satellite Advanced Very High Resolution Radiometer thermal signals measured in the volcanic area of Etna (Italy), Fluctuat. Noise Lett., 6 (3), 305-316.

Marchese, F., G. D'Angelo, M. Ciampa, C. Filizzola, N. Pergola and V. Tramutoli (2008): Assessing the potential of a robust satellite technique for volcanic activity monitoring: possible impacts on volcanic hazard mitigation, J.Volcanol. Geotherm. Res. (under review accepted).

Mosher, F.R. (1999): Four channel volcanic ash detection algorithm, Aviation Weather Center Staff Publication (available on line at: http://aviationweather.noaa.gov/ publications/mosher/paper3.html).

Patrick, M.R, J.L. Smellie, A.J.L. Harris, R. Wright, K. Dean, P. Izbekov, H. Garbeil and E. Pilger (2005): First recorded eruption of Belinda volcano (Montagu Island), South Sandwich Islands, Bull. Volcanol., 67, 415-422. 
Pappalardo, G., A. Amodeo, L. Mona, M. Pandolfi, N. Pergola and V. CuOMo (2004). Raman lidar observations of aerosol emitted during the 2002 Etna eruption. Geophys. Res. Lett., 31 (LXXXXX), doi: 10.1029/ 2003GL019073.

Pavolonis, M.J., F.F. Wayne, A.K. Heidinger and G.M. GaLlina (2006): A daytime complement to the reverse absorption technique for improved automated detection of volcanic ash, J. Atmos. Oceanic Technol., 23, 1422-1444.

Pergola, N., C. Pietrapertosa, T. Lacava and V. TramuTOLI, V. (2001). Robust 741 satellite techniques for volcanic eruptions monitoring, Ann. Geophysics, 44 (2), 167-177.

Pergola, N., V. Tramutoli, F. Marchese, I. Scaffidi and T. LACAVA (2004a): Improving volcanic ash cloud detection by a robust satellite technique, Remote Sensing Environ., 90, 1-22.

Pergola, N., V. Tramutoli and F. Marchese (2004b): Automated detection of thermal features of active volcanoes by means of Infrared AVHRR records, Remote Sensing Environ., 93 (3), 311-327.

PRATA, A.J. (1989): Observations of volcanic ash clouds in the $1012 \mu \mathrm{m} 756$ window using AVHRR/2 data, Inter. J. Remote Sensing, 10, 751-761.

Rose, W.I. and D.J. ScHNEIDER, (1996). Satellite images offer aircraft protection from volcanic ash clouds, Eos, Trans. Am. Geophys. Un., 77, 529-530.

Rose, W.I., G.J.S. BluTh and G.G.J. ERnst (2000). Integrating retrievals of volcanic cloud characteristics from satellite remote sensors: a summary, Philos. Trans. $R$. Soc. London. 358, 1585-160.
TRAmuTOLI, V. (1998): Robust AVHRR Techniques (RAT) for environmental monitoring: theory and applications, in Earth Surface Remote Sensing, edited by G. CECCHI and E. ZiLIOLI, Proceedings of SPIE 3496,101-113.

Tramutoli, V. (2005): Robust Satellite Techniques (RST) for natural and environmental hazards monitoring and mitigation: ten years of successful applications, in The 9th International Symposium on Physical Measurements and Signatures in Remote Sensing, edited by Shunlin Liang, Jiyuan LiU, Xiaowen Li, RongGao LiU and M. Schaepman, Beijing (China), ISPRS, XXXVI (7/W20), 792-795.

Wen, S. and W.I. Rose (1994): Retrieval of sizes and total masses of particles in 821 volcanic clouds using AVHRR bands 4 and 5, J. Geophys. Res., 99, 54215431.

Wright, R., L. Flynn, H. Garbeil, A. Harris and E. PilGER (2002a): Automated volcanic eruption detection using MODIS, Remote Sensing Environ., 82, 135-155.

Wright, R., S. De La CruZ-Reyna, A.J.L. Harris, L.P. FlYNN and J.J. GoMEZ-PALACIOS (2002b): Infrared satellite monitoring at Popocatepetl: explosions, exhalations, and cycles of dome growth, J. Geophys. Res. (Solid Earth), 107, 10.1029/2000JB000125

Wright, R., L.P. FlynN, H. Garbeil, A.J.L. HARris and E. PILGER (2004): MODVOLC: near-real-time thermal monitoring of global volcanism, J. Volcanol. Geotherm. Res., 135, 29-49.

Wright, R., S.A. CARN and L.P. FlynN (2005): A satellite chronology of the May-June 2003 eruption of Anatahan volcano, J. Volcanol. Geotherm. Res., 146, 102116. 